\title{
VACÚOLOS DE GÁS E FLUTUAÇÃO EM DIFFLUGIA MITRIFORMIS WALLICH (PROTISTA, RHIZOPODA, TESTACEOLOBOSEA)
}

\author{
Vladimir Stolzenberg Torres ${ }^{1}$
}

\begin{abstract}
Gas Vacuoles and flotation in DifFlugia Mitriformis Wallich (Protista, Rhizopoda, Testaceolobosea). The natural formation of gas vacuoles as a method of locomotion is described for Difflugia mitriformis Wallich, 1984. These vacuoles may contain different compositions of gases, basicly carbodioxyde or oxigen, with a membranous limitation similar or identical to other types of vacuoles. Those vacuoles are utilised by the organism as a mode of dislocation from the bottom to the water surface by flotation permiting better conditions for the survival of the individual, with the consequence of the perpetuance of the taxon.

KEY WORDS. Gas vacuoles, Difflugia mitriformis, flotation
\end{abstract}

BLES (1929) observou e sumarizou o processo de formação de vacúolos de gás em espécies de Arcella Ehrenberg, 1830. Nos experimentos realizados por BLES (1929), ENGELMANN (1869) e ODGEN (1991) a formação de vacúolos de gás foi induzida. SCHIMIDT-NIELSEN (1970) correlacionou o comportamento dos gases com os organismos e seu papel no metabolismo. O comportamento observado em A.discoides Ehrenberg, 1830 por ODGEN (1991) em muito assemelha-se ao constatado em Difflugia mitriformis Wallich, 1864.

Tal similaridade e o fato de que em todos os experimentos relatados foi induzida a formação de vacúolos, diferentemente do aqui apresentado, onde não houve uma indução intencional, proporciona objetivo e justificativa para a realização deste trabalho.

\section{MATERIAL \& MÉTODOS}

Os indivíduos utilizados neste estudo foram obtidos através de amostras d'água coletadas em diferentes pontos (Fig. 1) de Porto Alegre (Rio Grande do Sul) durante o ano de 1993. Foram estabelecidas culturas de clones conforme JEBRAM (1993) e TORRES \& JEBRAM (1993).

Desde o início, os cultivos foram constantemente vigiados a fim de se verificar o surgimento dos primeiros indivíduos com vacúolos.

Os organismos mantidos em tacinhas de cultivo (Fig. 2), foram examinados e fotografados em microscopia de contraste de fase.

1) Laboratório de Protistologia, Instituto de Biociências, Pontificia Universidade Católica do Rio Grande do Sul. Avenida Ipiranga 6681, prédio 12, 90619-900 Porto Alegre, Rio Grande do Sul, Brasil. 


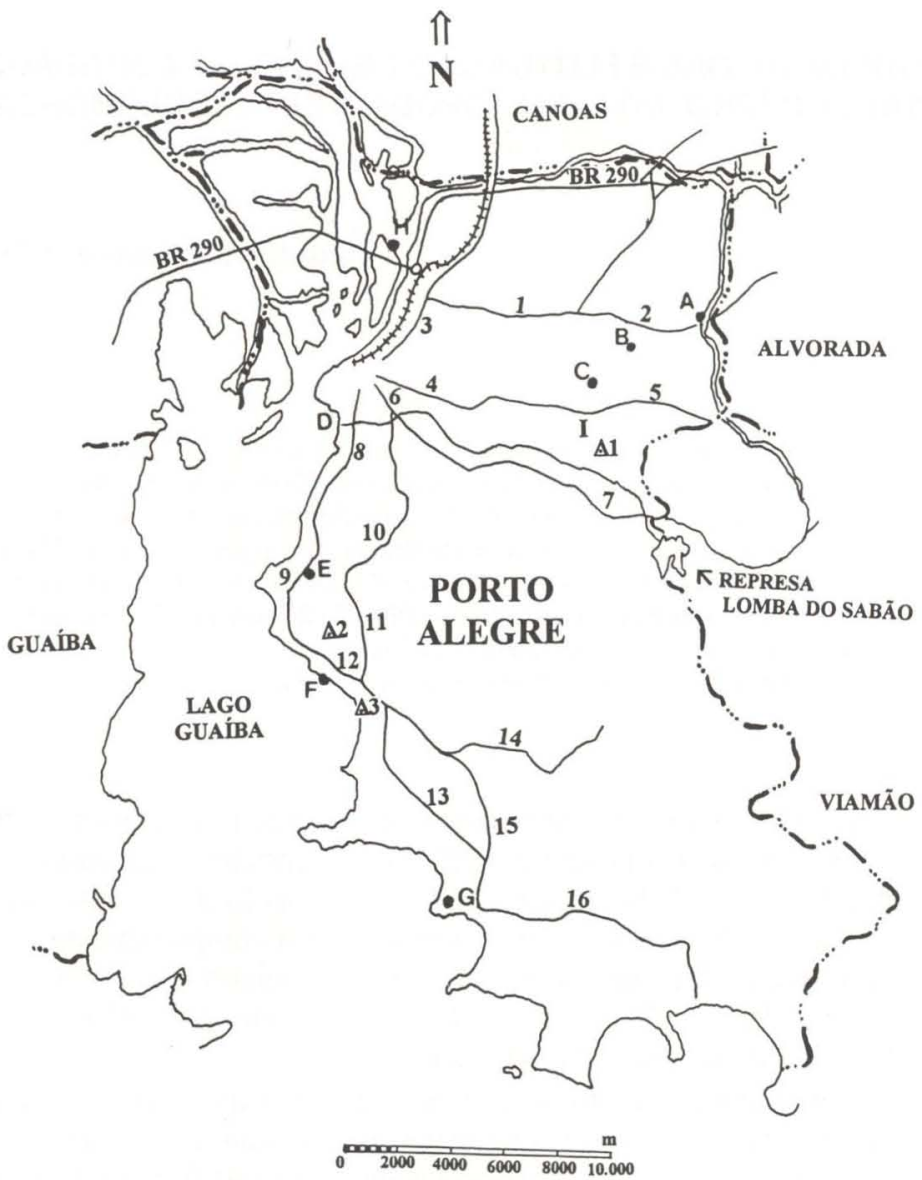

\begin{tabular}{|c|c|c|c|}
\hline \multicolumn{4}{|c|}{ CONVENÇŌES } \\
\hline$+n$ & Linha do Trensurb & 7 & Av. Bento Gonçalves \\
\hline$\Delta 1$ & Morre Santana - 311,20 m & 8 & Av. Borges de Medeiros \\
\hline$\Delta \mathbf{2}$ & Morro do Osso - 188,00 m & 9 & Av. Icaraí \\
\hline$\Delta \mathbf{3}$ & Morro do Sabiá - 40,00 m & 10 & Av. Carlos Barbosa \\
\hline 1 & Av. Assis Brasil & 11 & Av. Cavalhada \\
\hline 2 & Av. Baltazar de Oliveira Garcia & 12 & Av. Coronel Marcos \\
\hline 3 & Av. Farrapos & 13 & Estrada da Serraria \\
\hline 4 & Av. Osvaldo Aranha & 14 & Estrada Edgar P. de Castro \\
\hline 5 & Av. Protásio Alves & 15 & Estrada Juca Batista \\
\hline 6 & Av. João Pessoa & 16 & Estrada do Lami \\
\hline
\end{tabular}

Fig. 1. Lugares de coleta assinalados por um pequeno ponto preto. (A) Arroio Dornelles; (B) banhado junto ao Parque Chico Mendes; (C) Arroio no Sitio do Vô Chico; (D) Arroio Dilúvio; (E) Arroio Cavalhada; (F) Arroio Capivara; (G) Arroio na Heitor Vieira; (H) Ilha do Pavão; (I) no Morro Santana não houve um local específico para coletas, a escolha foi aleatória, em pequenas poças de água. 


\section{Estrato} Superior

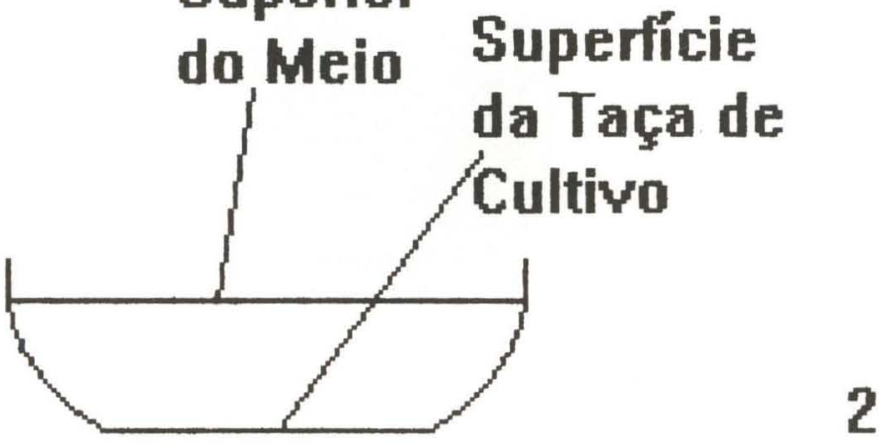

\section{Estrato} Superior

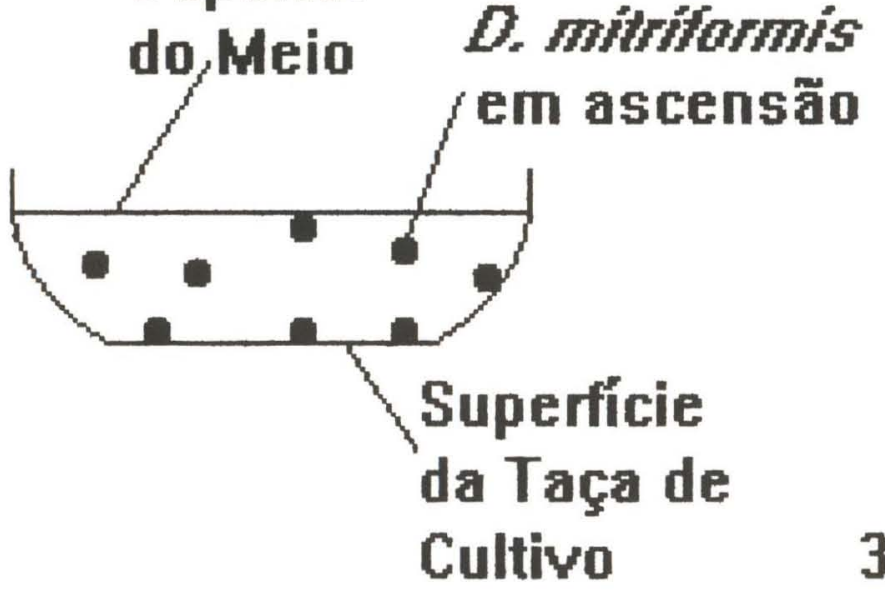

Figs 2-3. (2) Esquema do frasco de cultivo; (3) indivíduos de Difflugia mitriformis em processo de ascensão ao estrato superior do meio.

\section{RESULTADOS}

A testa de D. mitriformis caracteriza-se por apresentar uma forma ovalada. Ela é constituída de uma matriz rica em proteínas e glicoproteínas provenientes da coalescência de "grânulos testagênicos", estes originados no complexo de Golgi (BONNET et al. 1979), sendo finamente alveolada, à qual são cimentados materiais inorgânicos aglutinantes em especial partículas arenáceas. 

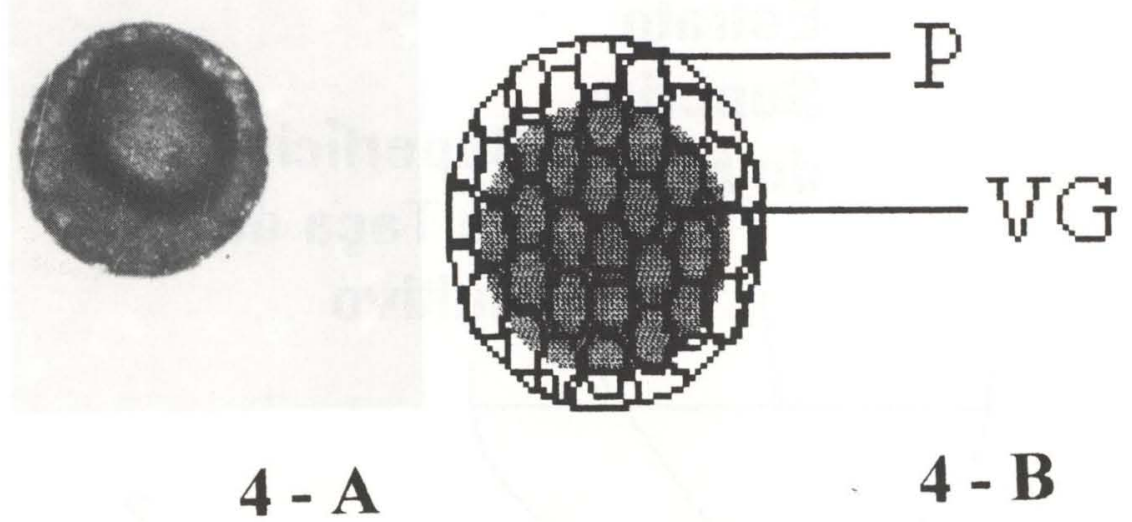

Fig. 4. Vacúolo de gás situado junto a região superior da testa. (A) Foto do organismo; (B) figura esquemática. (P) partículas da testa, (VG) vacúolo de gás.
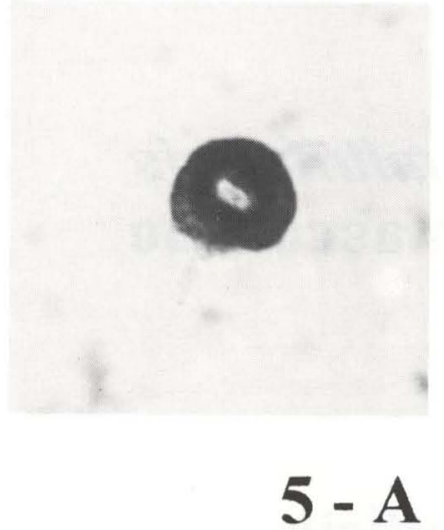
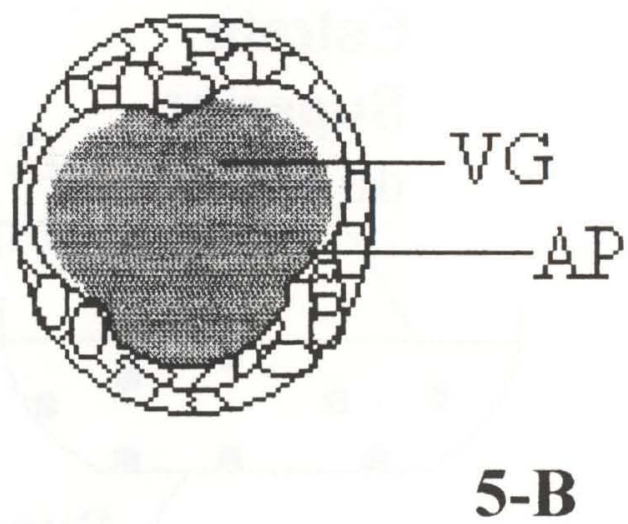

Fig. 5. Vacúolo de gás situado junto a região inferior (oral) da testa. (A) foto do organismo; (B) figura esquemática. (AP) abertura pilomar, (VG) vacúolo de gás.

A formação de vacúolos foi observada em espécimes isolados e clonados, três semanas após sua inoculação em meio de cultura, quando eles migraram (Fig. 3) do frasco para o estrato superior do meio de cultivo. Nesta fase, normalmente observa-se uma lâmina de bactérias na superfície do frasco.

Os vacúolos de gás formam-se dentro de sítios específicos no citoplasma, sendo então conduzidos para a região situada junto a parte superior ou inferior interna da testa (Figs 4, 5), de forma diferente, portanto, da ocorrente em Arcella (SCHIMIDT-NiELSEN 1970; ODGEN 1991) onde estas deslocam-se espacialmente pelo citoplasma junto ao perímetro da mesma.

Os vacúolos, independentemente do número formado inicialmente, deslocam-se para a região superior ou inferior interna da testa onde fusionam-se formando geralmente um único grande vacúolo, este se expande por acoplamento de novos 
pequenos vacúolos até ocupar aproximadamente $80 \%$ da superfície dorsal da testa, assumindo uma forma esférica (Figs 6, 7).

Conforme observado, o processo de formação de vacúolos e ascendência no meio de cultivo (Fig. 8) é mais acentuado quando do esgotamento dos nutrientes do meio, nas camadas mais inferiores. Um mecanismo de "fuga" é então estabelecido, o que possibilita o movimento de ascensão. Nem todos os indivíduos desenvolvem este mecanismo e a maior parte acaba por morrer.

O mecanismo de "fuga" é a forma através da qual, por ação de estímulos do meio, o testáceo começa a formação de vacúolos de gás que possibilitarão a ascensão-deslocamento vertical.

Os indivíduos que não se deslocam, por não conseguirem produzir os vacúolos de gás ou por não o fazer a tempo, morrem por razões diversas como inanição, queda na taxa de oxigênio dissolvido e aumento na concentração do meio provocando forte pressão osmótica (LEVEAU \& BOUIX 1985; DUMONT \& MEESTER 1990).

Os indivíduos flutuantes encontrando organismos fototróficos e outros como alimento, além de encontrar material inorgânico adequado, conseguem mesmo se reproduzir (Figs 9-11).
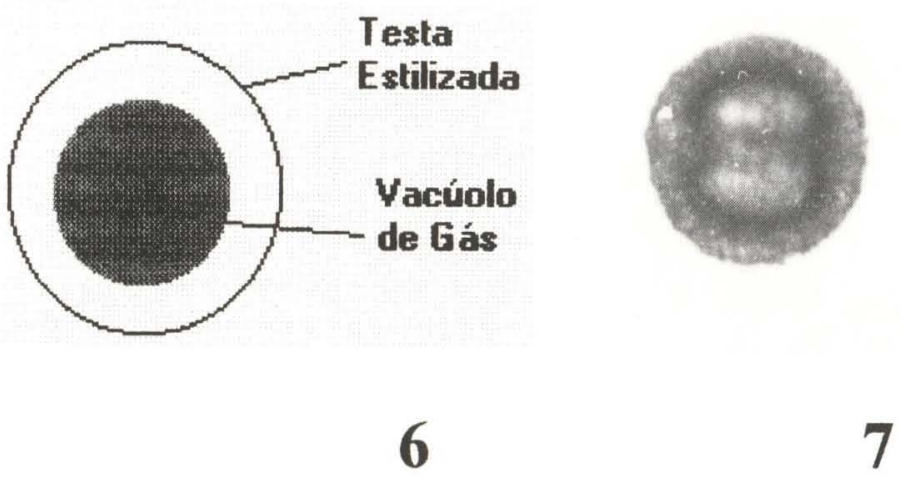

Figs 6-7. (6) Testa estilizada de Diffuglia mitriformis, em vista dorsal e com vacúolo de gás ao centro; (7) organismo em cultivo apresentando dois grandes vacúolos de gás; um fato raro nesta espécie.

\section{DISCUSSÃO E CONCLUSÕES}

Conforme BACHOFEN (1991) (Tab. I) os microorganismos podem produzir e consumir uma série de diferentes gases de acordo com a capacidade de cada táxon.

Difflugia mitriformis não é exceção a esta regra, consumindo oxigênio e produzindo dióxido de carbono. Suspeita-se que outros gases sejam também utilizados ou produzidos, embora não se possa afirmar tal fato.

Sendo D. mitriformis um organismo aeróbico, é de se esperar que a composição dos vacúolos seja de dióxido de carbono proveniente de ação metabólica ou oxigênio retido em grandes quantidades. 


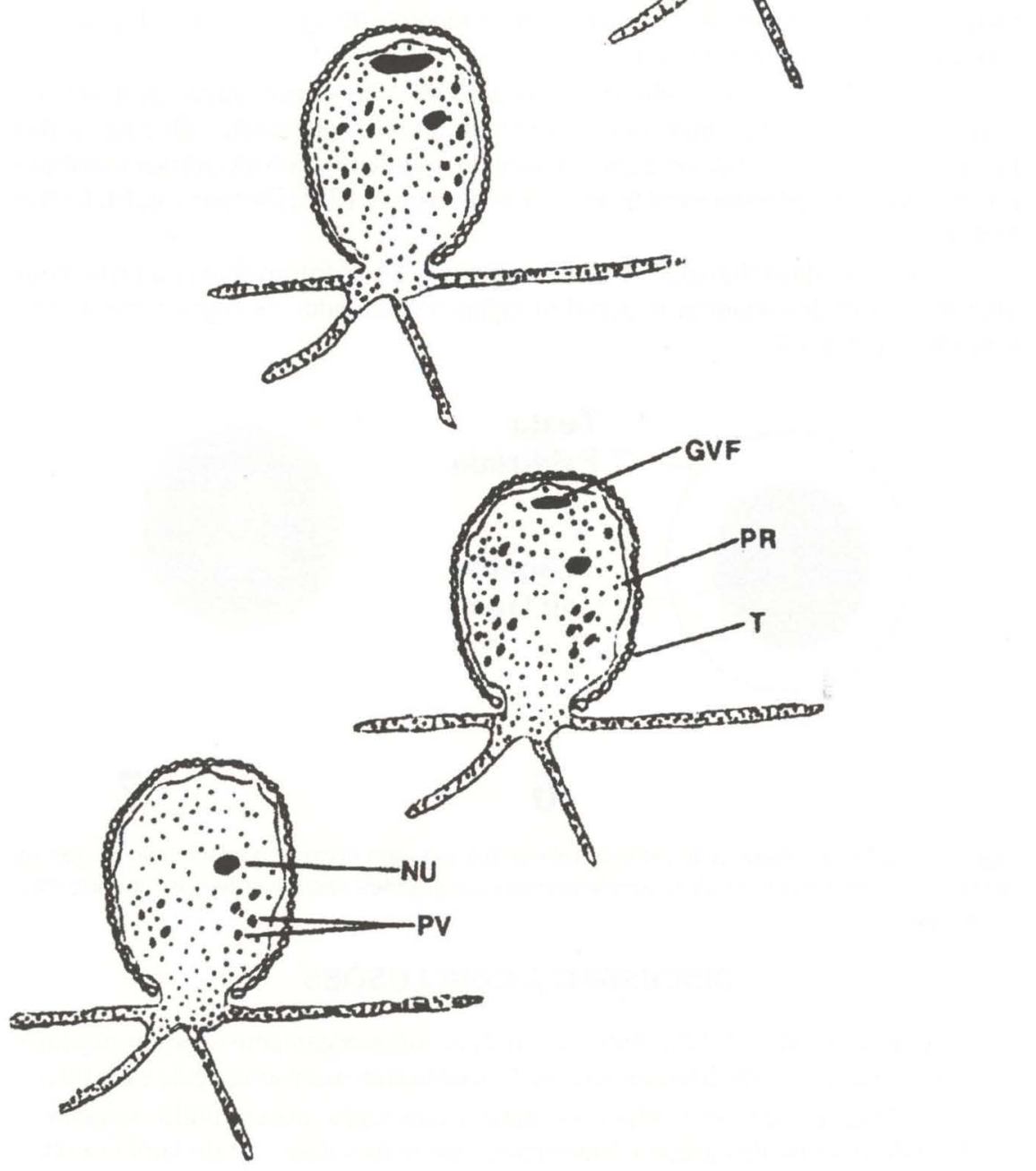

Fig. 8. A formação de vacúolos de gás e o movimento de ascensão em Difflugia mitriformis. (NU) núcleo, (PV) primeiros vacúolos em formação, (GVF) grande vacúolo em formação, (PR) protoplasma, (GV) grande vacúolo, (T) testa. 


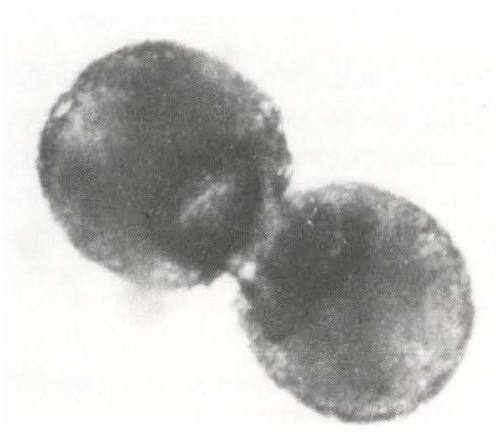

9

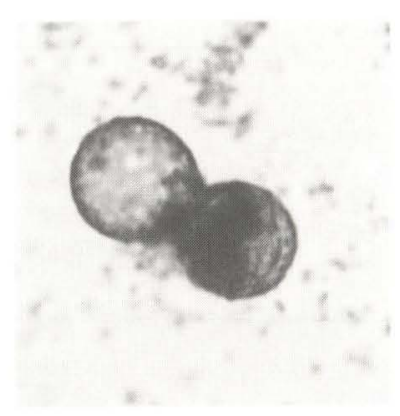

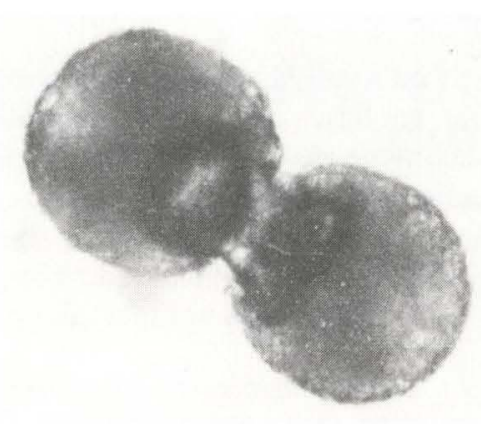

10

\section{1}

Figs 9-11. Reprodução por fissão binária de indivíduo de Difflugia mitriformis. (9) O vínculo citoplamástico é ainda bem visivel e em segundo plano há um filme bacteriano; (10) já iniciada contração, vínculo citoplasmático e as células já estão quase divididos; (11) célula morta por razões desconhecidas, observa-se em segundo plano a presença de filme bacteriano e silica em pó em suspensão.

Qualquer que seja o gás dos vacúolos, é efetiva a presença de uma membrana vacuolar (HUSZAR 1977; WALSBY 1977), por ser o dióxido de carbono tóxico em certas concentrações - variável para cada táxon, assim como o oxigênio, o qual pode se unir a radicais livres e prejudicar a estrutura do DNA, destruir membranas lipídicas e inativar uma série de enzimas celulares (FRANK \& MASSARO 1980; DEBY 1991).

Conforme WALSBY (1977), esta membrana vacuolar se apresenta composta de uma estrutura protéica, sendo a face interna hidrófoba pela presença de aminoácidos alifáticos, o que parece lógico, pois apenas o gás ocorre internamente e a água não penetra nem por difusão.

Diferentemente de Arcella discoides, que leva aproximadamente dez minutos, e Arcella catinus (Penard, 1890), que leva cerca de 20 minutos para formar os vacúolos e se deslocar até a superfície do meio (ODGEN 1991), não foi possível determinar o tempo do mesmo processo em Diffuglia mitriformis. O tempo de duração, entretanto, deste vacúolo pode ser de horas, quando então parece se esvaziar e o protista volta ao substrato. 
FINLAY (1981) relata o comportamento de ciliados em migração periódica vertical, em busca de oxigênio. Considerando que o comportamento de formação de vacúolos de gás em $D$. mitriformis foi também observado nos habitats de origem dos organismos coletados, pode-se dizer que a ascensão permite, além da sobrevivência do indivíduo, a perpetuação da espécie e sua dispersão, uma vez que tais organismos podem facilmente aderir às pernas de outros animais ou à plumagem de aves, deste modo sendo transportados para outras regiões.

Tabela I. Gases produzidos ou consumidos por microorganismos. Médias de produção e consumo alobal são de aproximadamente $10^{14}$ alano (BACHOFEN 1991).

\begin{tabular}{lcc}
\hline \multicolumn{1}{c}{ Gás } & Produção & Consumo \\
\hline $\mathrm{H}_{2}$ & $0,07-0,10$ & 1,2 \\
$\mathrm{O}_{2}$ & $10^{3 *}$ & $10^{3}$ \\
\hline Compostos de carbono & $3.10^{3}$ & $3.10^{3}$ \\
$\mathrm{CO}_{2}$ & $5,3-8,3$ & $?$ \\
$\mathrm{CH}_{4}$ & $0,2-1,2$ & 5,0 \\
$\mathrm{CO}$ & $?$ & $?$ \\
$\mathrm{Hidrocarbonetos}$ & $?$ & 0,07 (para EUA) \\
Etileno & $?$ & $?$ \\
Ácidos voláteis oleosos & $?, 6-2,6$ & 1,75 \\
\hline $\mathrm{Compostos} \mathrm{de} \mathrm{nitrogênio}$ & 0,77 & $?$ \\
$\mathrm{~N}_{2}$ & 11,9 & 6,0 \\
$\mathrm{~N}_{2} \mathrm{O}$ & $?$ & $?$ \\
$\mathrm{NO}_{x}$ & $?, 98$ & $?$ \\
$\mathrm{NH}_{3}$ & $?$ & $?$ \\
\hline $\mathrm{Compostos} \mathrm{sulforosos}_{\mathrm{H}_{2} \mathrm{~S}}$ & $?$ & $?$ \\
$\mathrm{SO}_{2}$ & $?$ & $?$ \\
$(\mathrm{CH}$ & & \\
$\left(\mathrm{C}_{2} \mathrm{H}_{5}\right)_{2} \mathrm{~S}$ & & $?$
\end{tabular}

*. Por organismos fototróficos.

\section{REFERÊNCIAS BIBLIOGRÁFICAS}

BACHOFEn, R. 1991. Gas metabolism of Microorganisms. Experimentia 47: 508-513

BLes, E.J. 1929. Arcella. A Study in Cell Physiology. Q. J. Microscop. Sci. 72: 527-648.

BoNNET, L. 1979. Nouvelles observations sur l'ustrastructure de la paroi de la thèque chez les Thécamoebiens (Rhizopodes Testacés). C.R. Acad. Sci. Serie D, Paris, 288: 227-230.

DeBY, C. 1991. La Bioquímica del Oxigeno. Mundo Científico 111 (11): 286-294.

Dumont, H.J. \& MeEster. L. DE. 1990. Are Contrasting Patterns of Vertical Migration in Zooplankton the Result of Differential Natural Selection? Rev. Brasil. Biol. 50 (4): 867-874. 
Engelmann, T.W. 1869. Sur le Développement Périodique de Gaz dans le Protoplasma des Arcelles vivantes. Archs néerl. Sci. 4: 424-173

FinLAY, B.J. 1981. Oxygen Availability and Seasonal Migrations of Ciliated Protozoa in a Freshwater Lake. Jour. Gen. Microbiology 123: 173-178.

Frank, L. \& D. Massaro. 1980. Toxidad por el Oxigeno. Amer. J. Med. 69: 117-126.

Huszar, V.L. DE M. 1977. Contribuição ao Conhecimento das Algas Planctônicas do Lago da Barragem Santa Bárbara, Pelotas, Rio Grnade do Sul, Brasil. Dissertação de Mestrado, não publicada, Universidade Federal do Rio Grande do Sul, Porto Alegre, 143p.

JeBram, D.H.A. 1993. Métodos básicos e novos para o cultivo de Protistas livres.

Comun. Mus. Ciênc. PUCRS, Porto Alegre, 50: 3-20.

Leveau, J-Y. \& M. BouiX. 1985. Cinéticas Microbianas. In: R. Scriban (Ed.). Biotecnologia. São Paulo, Manole, 489p.

Odgen, C.G. 1991. Gas Vacuoles and Flotation in the Testate Amoeba Arcella discoides. J. Protozool. 38 (3): 269-270.

SCHIMIDT-NIELSEN, K. 1970. Animal physiology in foundations of modern biology series. New Jersey, Englewoodcliffs, $3^{\text {rd }}$ edition.

TORRES, V.S. \& D.H.A. JeBram. 1993. Arcella gibbosa microsoma var.n. (Protozoa: Sarcodina, Arcellinida) descrição e observações feitas em seu cultivo. Biotemas, Porto Alegre, 6 (2): 20-29. 1994. Amebas Testáceas Ocorrentes na Região de Porto Alegre, RS. Biotemas, Porto Alegre, 7 (1/2): 65-78.

Walsby, A.E. 1977. The Gas Vacuoles of Blue-Green Algae. Sci. Amer. 237 (2): 90-97. 